\title{
Posttraumatic lateral ankle pain
}

\author{
Michele Pansini • Stefan Schlosser • Aline R. Buck • \\ Florian M. Buck
}

Received: 13 October 2010 /Revised: 13 January 2011 / Accepted: 24 January 2011 /Published online: 22 February 2011

(C) ISS 2011

\section{Diagnosis}

Soft tissue foreign body (STFB) simulating a necrotic Os peroneum $(\mathrm{OP})$.

\section{Discussion}

One of the most common errors in the diagnosis of a STFB is to overlook it, especially if the medical history is misleading and it is not obvious from clinical examination. It has been reported that $38 \%$ of retained foreign bodies can be overlooked at the initial examination [1]. In this case, the patient did not mention that a soft tissue wound was cleaned and stitched with two threads after the accident. The patient only reported tenderness on the lateral ankle whereas other typical symptoms such as swelling, cellulitis,

The case presentation can be found at doi:10.1007/s00256-011-1117-3.

M. Pansini · F. M. Buck $(\bowtie)$

Department of Radiology and Nuclear Medicine,

University Hospital of Basel,

Petersgraben 4,

4031 Basel, Switzerland

e-mail: florian.buck@gmail.com

S. Schlosser

Department of Surgery, University Hospital of Basel,

Petersgraben 4,

4031 Basel, Switzerland

\section{A. R. Buck}

Department of Internal Medicine, Triemli City Hospital,

Birmensdorferstrasse 497,

8063 Zurich, Switzerland inclusions cysts, abscess formation, and nerve laceration, were not present $[1,2]$.

Radiographs are the modality of choice to identify radiopaque STFB [2]. However, STFB consisting of wood or other radiolucent material like plastic or glass may need ultrasonography, computed tomography, or magnetic resonance imaging to establish the correct diagnosis [2-4].

In the presented case, the SFTB had a density similar to necrotic bone compared to adjacent bony structures and was situated slightly more lateral than an OP. Typically, the OP is an oval-shaped or round sesamoid ossicle located within the distal peroneus longus tendon usually in the region of the cuboid tunnel. It is one of the most common ossicles in the foot with a prevalence of $26 \%$ in its ossified form. It is bipartite or multipartite in about $25-30 \%$ of cases [5-7]. However, necrosis of OP is very rare and has been described in the literature only once [8]. In case of fracture, increased density of a sesamoid bone may also be caused by callus formation.

Another possible differential diagnosis would have been the "painful os peroneum syndrome", also called POPS, described by Sobel et al. [9]. In this syndrome, the OP often appears sclerotic and fragmented on radiographs, and a fracture, diastasis, or migration of the OP may be revealed. Clinical findings may include a thickening of the peroneus longus tendon at the cuboid tunnel and/or tenderness over the cuboid [10].

However, on the oblique lateral radiograph, the STFB seemed to be too far lateral as well as slightly larger than a normal OP. Furthermore, the inconspicuous contour of the adjacent bones excluded an avulsion-type fracture and the anterior-posterior and the oblique lateral view showed some splintered radiopaque material around the STFB. At surgery, a $14 \times 11 \times 8 \mathrm{~mm}$ stone was founded adjacent to the peroneus 
Fig. 1 At surgery a 14 x 11 x $8 \mathrm{~mm}$ stone was founded adjacent to the peroneus longus tendon

longus tendon (Fig. 1). Based on radiographs, the diagnosis of STFB was established. The differential diagnosis included OP necrosis even though the STFB was slightly too large, too dense, and too laterally located to be interpreted as a normal OP. An additional CT or MR scan would have been helpful in recognizing the lack of trabecular bone structure and excluding bone necrosis.

In conclusion, the detection of STFB of the foot can be difficult. Radio-opaque STFB may mimic normal or diseased sesamoid bones and an accurate analysis of the clinical history of the patient is crucial for the radiologist to unravel such an uncommon diagnosis.

Conflict of interest The authors declare that there are no conflicts of interest.

\section{References}

1. Anderson MA, Newmeyer 3rd WL, Kilgore Jr ES. Diagnosis and treatment of retained foreign bodies in the hand. Am J Surg. 1982;144(1):63-7.

2. Hunter TB, Taljanovic MS. Foreign bodies. Radiographics. 2003;23(3):731-57.

3. Horton LK, Jacobson JA, Powell A, Fessell DP, Hayes CW. Sonography and radiography of soft-tissue foreign bodies. AJR Am J Roentgenol. 2001;176(5):1155-9.

4. Oikarinen KS, Nieminen TM, Makarainen H, Pyhtinen J. Visibility of foreign bodies in soft tissue in plain radiographs, computed tomography, magnetic resonance imaging, and ultrasound. An in vitro study. Int J Oral Maxillofac Surg. 1993;22 (2):119-24.

5. Peterson JJ, Bancroft LW. Os peroneal fracture with associated peroneus longus tendinopathy. AJR Am J Roentgenol. 2001;177 (1):257-8.

6. Miller TT. Painful accessory bones of the foot. Semin Musculoskelet Radiol. 2002;6(2):153-61.

7. Mellado JM, Ramos A, Salvado E, Camins A, Danus M, Sauri A. Accessory ossicles and sesamoid bones of the ankle and foot: imaging findings, clinical significance and differential diagnosis. Eur Radiol. 2003;13 Suppl 4:L164-177.

8. Sawada S, Tatsuzawa Y, Hashimoto T, Otake S. Rare case of aseptic necrosis of the os peroneum. Seikei Geka. 1968;19(14):1257-9.

9. Sobel M, Pavlov H, Geppert MJ, Thompson FM, DiCarlo EF, Davis WH. Painful os peroneum syndrome: a spectrum of conditions responsible for plantar lateral foot pain. Foot Ankle Int. 1994;15(3):112-24.

10. Di Giovanni C, Greisberg J. Core knowledge in orthopaedics: foot and ankle. Elsevier, 2007. 